\title{
A simulation and analysis of electron beam welding based on dynamic focus
}

\author{
Weipeng Yin, Shouqi Wei \\ Guilin University of electronic technology, Guilin 541004, China
}

\begin{abstract}
According to the characteristics of electron beam welding (EBW) heat source and thermal effect, a mathematic model of rotary Gaussion body heat source based on the dynamic welding focus was developed, and the finite element model (FEM) is established. A numerical simulation experiments of the vacuum EBW were made with the Q235 steel plate of $50 \mathrm{~mm}$ in thickness. This simulation was included the temperature field distribution in fixed focus welding and the temperature field distribution in dynamic focus welding. Results shown that the welding depth was unstable when the frequency was at $10 \mathrm{~Hz}$ and the welding depth was stable relatively when the frequency was at $30 \mathrm{~Hz}$ in the dynamic focus welding. Compared to the fixed focal welding, when focus moving frequency was right, the dynamic focus welding could increase the depth of welding. The simulation of the dynamic focus welding shapes were consistent with the characteristics of the actual test of EBW.
\end{abstract}

KEYWORD: Electron beam welding, Dynamic focus, Power density, Dynamic heat source.

\section{INTRODUCTION}

The influencing factors of EBW mainly include welding parameters, geometric parameters and physical parameters, and welding parameters is closely related to the quality of welding seam and welding pool. The main welding parameters include accelerating voltage, beam intensity, welding speed and welding focus position, etc. However, in these parameters, the focus position has a great influence on the longitudinal power density distribution in the welding pool(Yi Luo, 2010).In the fixed focus welding, different focus position has a different weld depth and weld width, and they reached the maximum or minimum at certain focus location(Ping Gong, 2008).Tests show that, in the same welding conditions, the welding depth and the distance from the welding focus location to the workpiece surface is approximate parabola relationship (E.Kolleva, 2005).Many literatures have showed that the welding focus position has an important influence on welding pool shape (Ningmao Qiu, 1996). The current EBW study mostly concentrated in the fixed focus welding. However, the change of the welding focus position has a great influence on welding depth in the thickness workpiece welding. Based on finite element analysis software ANSYS analysis platform, this article simulate the EBW temperature field of Q235 steel, and realize preliminary forecast of weld depth and weld width in the EBW. Using the simulated process parameters carried out the EBW experiment based on Q235 steel and verified the reliability of simulation results.

\section{THE DYNAMIC FOCAL HEAT SOURCE MODEL}

The characteristics of EBW heat source model in the fixed focus welding is shown below:

(1) Along the axis direction, an increasing in power density was the increase of the depth.

(2) Along the radial direction, the power density decreases as the effective radius of the heat source increases.

In the dynamic focus welding, the focus position and welding depth changes over focus coil current. Different focus coil current has a different power distribution. In the paper, the dynamic welding focus heat source model based on the rotary Gaussion body heat source model is established. The power density distribution function of the dynamic focus is as follows:

$\mathrm{q}(\mathrm{x}, \mathrm{y}, \mathrm{z})=\frac{\mathrm{C}_{1} 9 \eta \mathrm{UI}_{\mathrm{b}}}{\pi \mathrm{hr}_{0}^{2}\left(1-\mathrm{e}^{-3}\right)} \bullet \mathrm{e}^{\left(\frac{(\mathrm{h}-\mathrm{z})^{2}}{\mathrm{~h}^{2}} \cdot \frac{9 \mathrm{r}^{2}}{\mathrm{r}_{0}^{2} \ln (\mathrm{z} / \mathrm{h})}\right)} \cdot \mathrm{e}^{(\beta \mathrm{hz})}$

Where $q(x, y, z)$ is the power density, $\mathrm{x}^{2}+\mathrm{y}^{2}=\mathrm{r}^{2}$, and $\mathrm{r}$ is ranged from 0 to $\mathrm{r}_{0}, \mathrm{z}$ is ranged from 0 to $h, \eta$ is effective power coefficient , $U$ is accelerating voltage, $\mathrm{I}_{\mathrm{b}}$ is beam current, $\mathrm{C}_{1}$ is heat source correction coefficient, $h$ is heat source height, $r_{0}$ is 
heat source maximum radius in work piece surface and $\beta$ is peak-power-density coefficient. Among them, the $h$ is linearly correlated with focus coil current, and $\beta$ is related with focus coil current.

The power density distribution in fixed focus welding is shown in figure 1 , when $\mathrm{h}=40 \mathrm{~mm}, \mathrm{U}=$ $60 \mathrm{kV}, \mathrm{I}_{\mathrm{b}}=100 \mathrm{~mA}, \mathrm{r}_{0}=3 \mathrm{~mm}$.

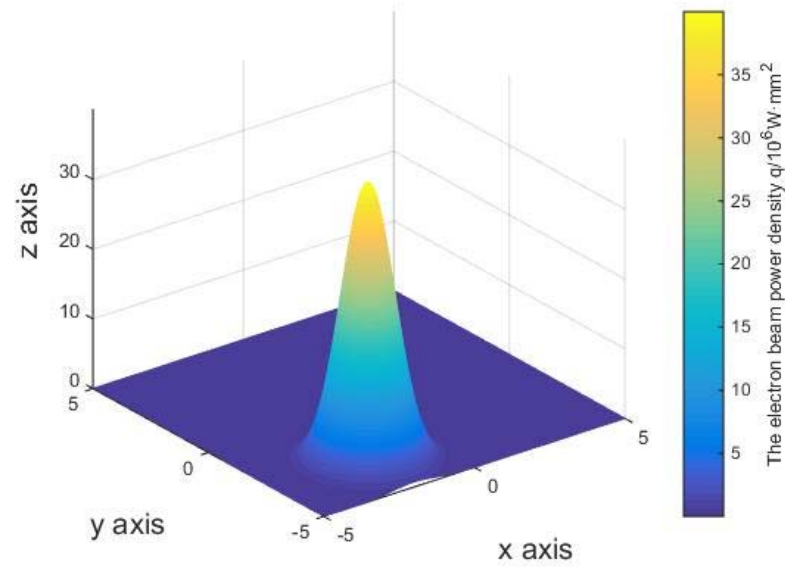

Figure.1 Power density distribution

\section{THE FINITE ELEMENT SIMULATION}

OF EBW BASED ON THE DYNAMIC FOCUS

During EBW process, there are a complex physical and chemical reaction between the welding heat source and the welding molten pool. So, it is need to simplify the welding factors in the process of simulation, and the simplifying process is as follows:

(1)The convection, radiation, chemical reaction of the melting pool is ignored in EBW.

(2)Welding process keep a constant speed and the heat energy density distribution is in accordance with the ideal heat source model established above.

\subsection{Establishing FEM}

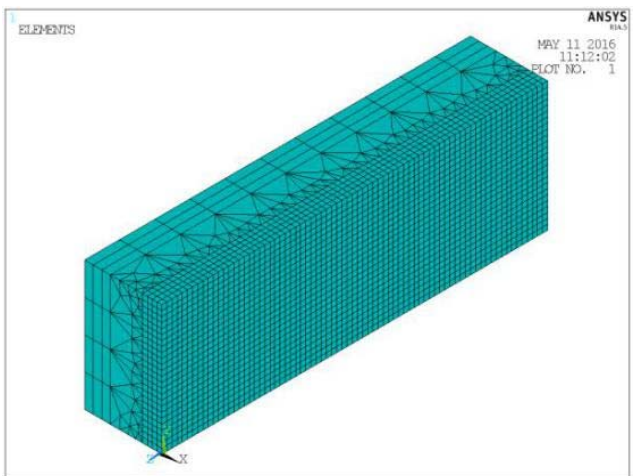

Figure.2 Finite element mesh used for the welding simulation.

Due to the geometric symmetry, the $1 / 2$ welding model based on Q235 steel plate is established. The temperature gradient in different areas is different in the welding heating process. So the meshing of FEM is uneven. In FEM, the weld area mesh is small mesh, and the area far away from the weld area is big mesh, and the middle section uses free mesh. The FEM mesh is shown in figure 2.The model adopts solid70 thermal analysis unit, and the whole model consist of 22,397 eigh-node hexahedron elements. It's a total of 16,438 nodes. The sizes of the FEM is $20 \mathrm{~mm} \times 12 \mathrm{~mm} \times 50 \mathrm{~mm}$.

\subsection{Electron beam welding process parameters}

According to the test plan, the accelerating voltage is $60 \mathrm{kV}$, and the beam current is $100 \mathrm{~mA}$, and the welding speed is $200 \mathrm{~mm} / \mathrm{min}$. When the welding focus is on the workpiece surface, the focus coil current is 345 $\mathrm{mA}$. When the welding focus is on the workpiece bottom, the focus coil current is $320 \mathrm{~mA}$. In fixed focus welding, the focus coil current is $335 \mathrm{~mA}$. As is shown in figure 3 , the focus coil current change over time at $10 \mathrm{~Hz}$. In dynamic focus welding, the welding frequency is $10 \mathrm{~Hz}$ and $30 \mathrm{~Hz}$ respectively.

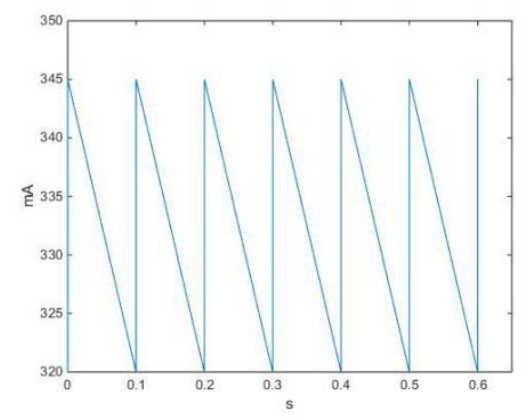

Figure.3 The focus coil current waveform at $10 \mathrm{~Hz}$

\subsection{The welding temperature field simulation and analysis}
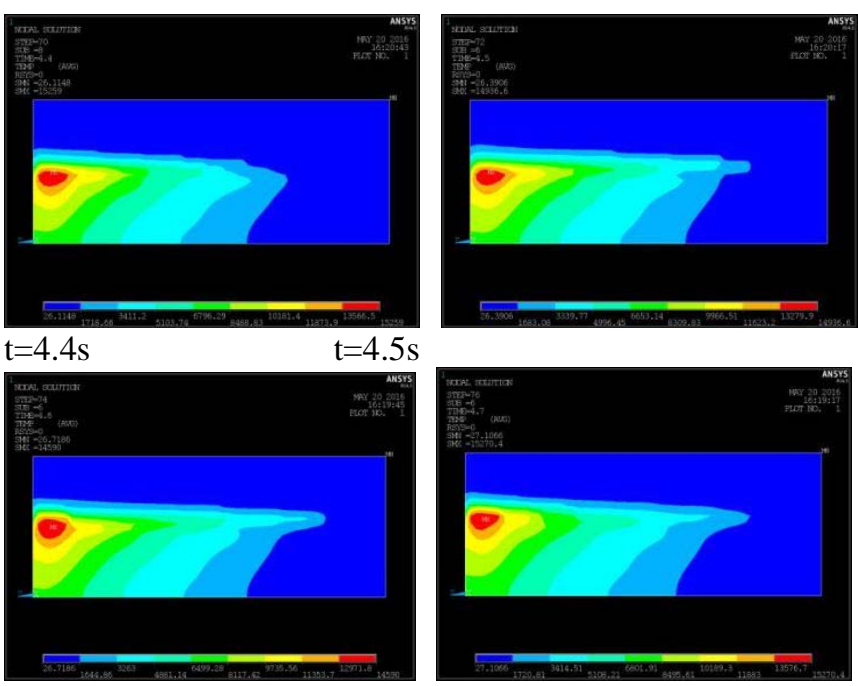

$\mathrm{t}=4.6 \mathrm{~s}$

$\mathrm{t}=4.7 \mathrm{~s}$

Figure.4 The welding graphics at $10 \mathrm{~Hz}$ 

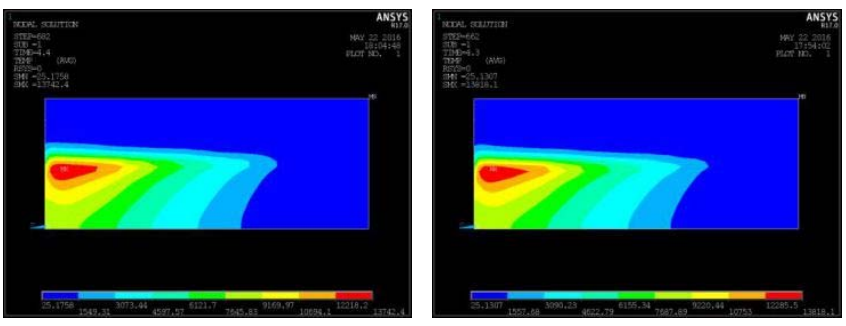

$\mathrm{t}=4.4 \mathrm{~s}$

$\mathrm{t}=4.3 \mathrm{~s}$

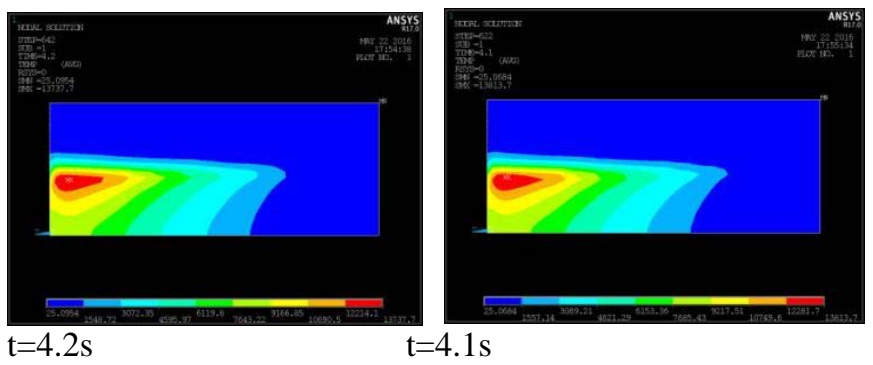

Figure.5 The welding graphics at $30 \mathrm{~Hz}$
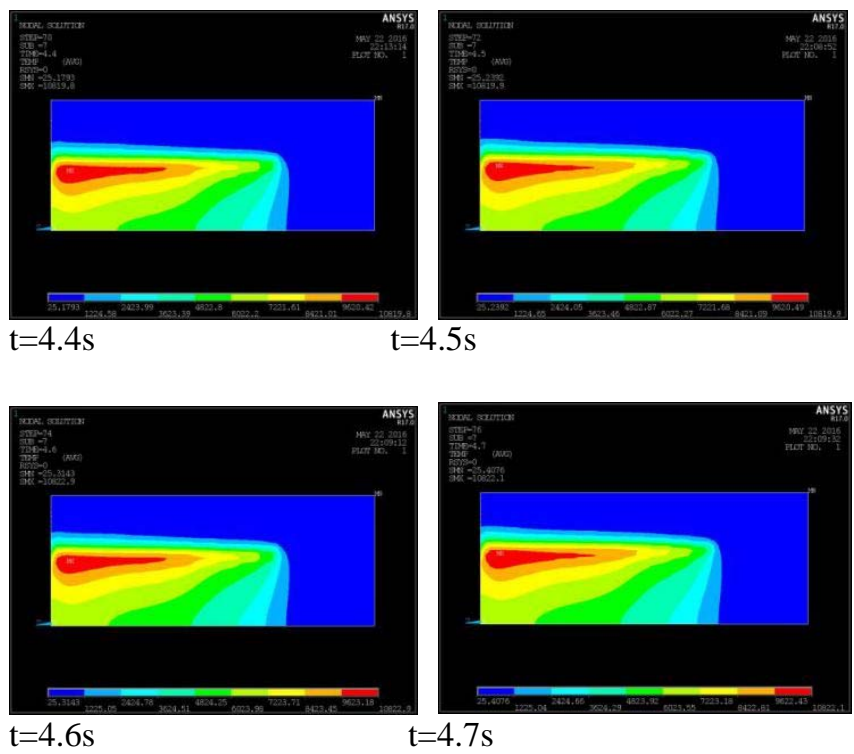

Figure.6 The welding graphics at $335 \mathrm{~mA}$

The Q235 steel melting point is $1870^{\circ} \mathrm{C}$. The figure 4 shows that the welding depth is not stable at $10 \mathrm{~Hz}$. This is because the moving speed of the welding focus is not matching with metal melting rate in the low frequency, and it result in instability in welding depth. The figure 5 shows that compared with $10 \mathrm{~Hz}$, the welding depth at $30 \mathrm{~Hz}$ slightly increased and is relatively stable. This is because when the moving speed of the welding focus is close to metal melting rate at $30 \mathrm{~Hz}$, the melting efficiency improve, and it makes the weld depth increase. The figure 6 shows when the focus coil current is $335 \mathrm{~mA}$, the weld depth is relatively stable. The comparison of figure 5 with figure 6 shows that the dynamic focus welding at $30 \mathrm{~Hz}$ can increase the welding depth. This is because there is a depth of field (DOF) near the welding focus, and within the DOF, electron beam has the highest power density. The high power density make EBW get a big welding depth and small welding width in the electron beam deep-penetration welding. If the focus position is fixed in the welding process, it is only the DOF that has a high melting efficiency effectively, and in other areas, the effective electron beam melting efficiency decreases due to the reduced beam power density. In the whole dynamic focus welding, the welding focus position is controlled by the circuit of the focus coil, and using the welding focus melt the bottom metal of the welding pool from beginning to end. In ideal circumstances, when the speed of the welding focus moving match with the metal melting rate, the average power density on the weld depth can be close to its maximum power density, and it will gain the biggest welding depth. The $30 \mathrm{~Hz}$ welding experiment illustrates this point. But when the welding frequency is not in line with the metal melting rate, weld depth is not stable, and the unstable welding deep will affect the welding quality.

\section{EXPERIMENT AND RESULT ANALYSIS}

According to the simulation condition, a welding experiment is tried in the vacuum environment.

Six groups welding experiment data at $10 \mathrm{~Hz}$ and $30 \mathrm{~Hz}$ is shown in table 1 , and the deep is depth of EBW, and the width is width of EBW in 1/2 welding depth.

Table 1 the welding depth and weld width data in dynamic focus welding

\begin{tabular}{ccccccc}
\hline Frequency $/ \mathrm{Hz}$ & Deep $/ \mathrm{mm}$ & Width $/ \mathrm{mm}$ & Deep $/ \mathrm{mm}$ & Width $/ \mathrm{mm}$ & Deep $/ \mathrm{mm}$ & Width $/ \mathrm{mm}$ \\
\hline \multirow{2}{*}{10} & 34.90 & 4.74 & 37.16 & 4.02 & 37.90 & 4.02 \\
& 35.10 & 4.54 & 36.58 & 5.52 & 37.82 & 5.52 \\
\multirow{2}{*}{30} & 38.40 & 5.94 & 38.10 & 5.62 & 38.52 & 5.62 \\
& 37.82 & 4.92 & 39.30 & 4.30 & 39.12 & 4.30 \\
\hline
\end{tabular}

Table 2 is the data of the weld depth and the weld width in $1 / 2$ welding depth, when focus coil current is $335 \mathrm{~mA}$.

In table 3, compared with the weld depth at $10 \mathrm{~Hz}$, when the frequency is at $30 \mathrm{~Hz}$, the welding depth is deeper, and the stability of the depth is relatively good. As can be seen from table 3 and table 4, an ap- propriate frequency can obtain a bigger deep in dynamic focus welding. When the frequency is not appropriate, the dynamic focus welding cannot increase the weld depth, and stability will be worse. In figure 7, the $a$ and $b$ is the weld morphology of the Q235 steel block at $10 \mathrm{~Hz}$ and at $30 \mathrm{~Hz}$ respectively. the c is the weld morphology of the Q235 steel block when the focus coil current is $335 \mathrm{~mA}$. The left and right 
side of the picture dare physical topography and simulated morphology at $10 \mathrm{~Hz}$ respectively, and the comparison shows that welding experiments and numerical simulation results are in good agreement.

Table 2 the welding depth and weld width data in fixed focus welding

\begin{tabular}{ccccccc}
\hline Current $/ \mathrm{mA}$ & Deep $/ \mathrm{mm}$ & Width $/ \mathrm{mm}$ & Deep $/ \mathrm{mm}$ & Width $/ \mathrm{mm}$ & Deep $/ \mathrm{mm}$ & Width $/ \mathrm{mm}$ \\
\hline \multirow{2}{*}{335} & 35.50 & 5.80 & 35.24 & 6.54 & 34.74 & 6.54 \\
& 34.36 & 6.62 & 34.30 & 6.56 & 34.46 & 6.56 \\
\hline
\end{tabular}

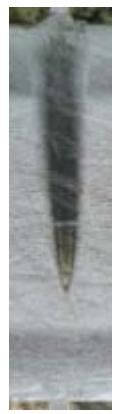

(a)

(b)
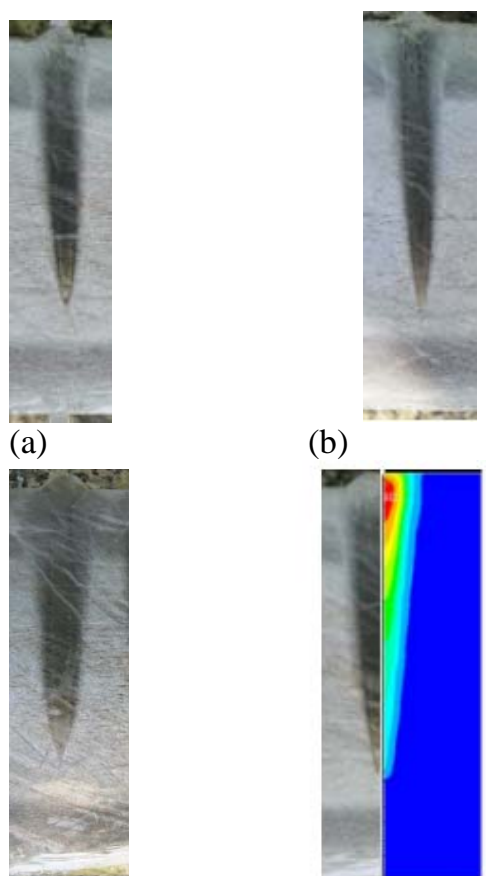

(c)

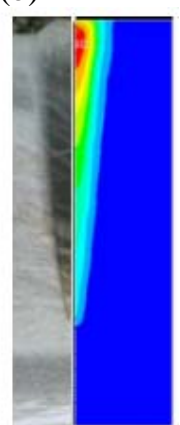

(d)

Figure.7 The weld morphology

\section{CONCLUSION}

The 3D dynamic focus heat source model based on electron beam finite element simulation of the Q235 steel has good applicability in welding.

The dynamic focus welding can increase the welding depth in the thickness work piece welding, when the welding frequency is in line with the metal melting rate. But the welding stability the will become worse, and it will affect the welding quality, when the welding frequency is not suitable.

\section{ACKNOWLEDGEMENT}

This work is supported by Innovation Project of Guangxi Graduate Education, China (Grant No. YCSZ2015143). The corresponding author is Weipeng Yin, Guilin University of Electronic Technology, and Email: 1275788220@qq.com.

\section{REFERENCES}

E.Kolleva.Electron bean weld parameters and thermal efficiency improvement.Vacuum 77 (2005)413-421.

Ningmao Qiu.The electron beam welding mechanism and methods of the deep welding effect.Research note.4 (1996)33-40.

Ping Gong,Yu Luo,Yajun Wang,and Zhiyu Mao. Effect of TC4 Titan alloy electron beam welding parameters on weld shape.Aerospace Manufacturing Technology.6(2008)72-75.

Yi Luo,Jinhe Liu,Hong Ye.An analytical model and tomographic calculation of vacuum EBW heat source. Vacuum.84(2010)857-863. 